\title{
Positive Correlation Between Japanese Cedar Pollen Numbers and the Development of Kawasaki Disease
}

\author{
Akira Awaya $^{1,2, *}$ and Koji Murayama ${ }^{3}$
}

\begin{abstract}
${ }^{I}$ Dermatology \& Epidemiology Research Institute (DERI) 4978 Totsuka-cho, Totsuka-ku, Yokohama, Kanagawa 2440003, Japan; ${ }^{2}$ Department of Genome System Science, Yokohama City University Seto 22-2, Kanazawa-Ku, Yokohama, Kanagawa 236-0027, Japan; ${ }^{3}$ Japan Meteorological Business Support Center (JMBSC) 3-17, KandaNishiki-cho Chiyoda-ku Tokyo 101-0054, Japan
\end{abstract}

\begin{abstract}
Objective: Kawasaki disease (KD), an acute febrile disease that induces systemic vasculitis in infants, has been proposed by Awaya and Sahashi in 2003 to be epidemiologically linked with pollen exposure. In this report, seasonal variation patterns of the monthly development of KD in 5,917 patients (Pt.) in Kanagawa, Japan were compared with the monthly pollen release numbers (Nos.) from 1991 to 2002. Methodology: A correlation coefficient (c.c.) matrix was generated using regression analyses of the correlation of KD onset and pollen exposure in each month. The percent of Japanese cedar pollen Nos. was calculated from the pollen numbers (Po.Nos.) of all the species surveyed in March and April throughout the years. Results: Significant c.c. associations were revealed between Po.Nos. from all species in March and KD Pt.Nos. in August (0.88), November (0.72), May (0.68), and April (0.66). Significant c.c. associations were also found between Po.Nos. from all species in April and KD Pt.Nos. in August (0.70), and between Po.Nos from all species in February and KD Pt.Nos. in July (0.62). Mean c.c. values of 0.60 in March, 0.47 in October, 0.45 in July, 0.35 in April, and 0.31 in February between Po.Nos. and KD Pt.Nos. were shown. February, March and April contributed 4.7\%, 40.6\% and $38.8 \%$ of the annual Po.Nos., respectively, of which $93.8 \%, 84.3 \%$ and $10.9 \%$ were from cedar pollen, respectively. Conclusions: A positive association was demonstrated between the Po.Nos. from all species, particularly cedar Po.Nos. in March, and the KD Pt.Nos. in the following several months.
\end{abstract}

Keywords: Association, delayed-type hypersensitivity, Japanese cedar pollen, Kawasaki disease, occurrence, pollen-induced disease, sensitization.

\section{INTRODUCTION}

First reported in 1962, Kawasaki disease (KD; mucocutaneous lymph node syndrome (MCLS)), is an acute febrile disease that induces systemic vasculitis in nursing infants [13]. Saito was the first to report Japanese cedar pollinosis, in 1963 [4]. Nakamura et al. reviewed a number of reports suggesting that the development of KD might be associated with bacterial or viral infection [5]. Lee et al. proposed that KD might be a hyperimmune reaction of genetically susceptible children to variants of normal environmental flora [6]. However, in 2003, Awaya and Sahashi first proposed that constitutionally allergic infants might develop KD upon contact with pollens [7]. This proposal was based on the fact that both KD and pollinosis were discovered continuously in the early 1960s, a time when increased amounts of cedar pollen were released due to the maturation of trees planted after World War II on a large scale, and when further motorization made a rapid advance in Japan [4].

A series of studies have examined the relation between the annual numbers (Nos.) of KD patients (Pt.) in Japan from 1965 to 2002 (a total of 190,000 people) and the amount of

*Address correspondence to this author at the Dermatology \& Epidemiology Research Institute (DERI) 4978 Totsuka-cho, Totsuka-ku, Yokohama, Kanagawa 244-0003, Japan; Tel: 81-45-861-4502; Fax: 81-45-861-4502; E-mail: awaya@home.email.ne.jp yearly released pollens at 8 surveyed sites [7]. Further, the KD Pt.Nos. in 4 prefectures around Tokyo Metropolis and the pollen Nos. (Po.Nos.) were evaluated at 4 nearby sites. Annual graphs of both KD Pt.Nos. and Po.Nos. showed that the first large peak of annual KD outbreak in 1979, the second in 1982, and the third in 1986 coincided with the peaks of massive pollen release in the same and previous years. Moreover, a positive correlation was demonstrated, not only in these 3 years, but also in 1995, around 2000, and in 2005, between the significant elevation of annual KD development in 4 prefectures and the prominent amount of total pollen released [8].

To examine seasonal variation patterns of onset of $\mathrm{KD}$ patients, and to elucidate more clearly that KD development was caused by sensitization with pollen and resensitization triggered by pollen exposure, we compared the monthly sums of Po.Nos. (surveyed daily) at Sagamihara in Kanagawa prefecture from 1991 to 2002, and the KD Pt.Nos. of each month (total of 5,917) in Kanagawa, also surveyed in the same period. By recording monthly developments of KD, a series of peaks, ascending from a low in September and October and extending consecutively from November to August, shows a characteristically sharp transient valley in February. This decline in KD Pt.Nos. is followed by peaks of Po.Nos., found mainly in March and April. Thus, this sudden descent of KD outbreaks in February juxtaposes the pattern found in influenza (Infl) epidemics in February [11]. In fact, 
the months with KD depression proved to coincide with peaks of Infl Pt.Nos. in the month of February [9]. In this study, we conducted extensive regression analyses of the correlation of KD and pollen exposure. We demonstrated that KD Pt.Nos. strongly correlated with the released pollen number from all species (Po.Nos.), particularly Japanese cedar pollens. This correlation was principally observed in March's, and also in April's and February's Po.Nos.

\section{METHODOLOGY}

\section{Location of Data Collection and Population}

Kanagawa prefecture (abbreviated as Kanagawa) in Japan, with an area of $2,415.47 \mathrm{~km}^{2}$ is located in the southwest side of Tokyo Metropolis (abbreviated as Tokyo), as shown in Supportive material 1. In 2007, Kanagawa had the second largest population $(8,893,264$ people), while Tokyo, with an area of $2,187.05 \mathrm{~km}^{2}$, had the largest population $(12,692,117$ people).

\section{Epidemiological Data of KD Patients}

All data were obtained from data stock previously used for published reports that had been approved by the ethics committees of their respective institutions [3]. While Tokyo had the largest patient numbers of KD (KD Pt.Nos.), the Kanagawa patient numbers were the second largest among all the local 47 prefectures of Japan from 1997 to 2008 [3]. Individual data of $5,917 \mathrm{KD}$ patients in Kanagawa from 1991 to 2002, including the dates of hospital admission and length of stay, were kindly provided by Professors Yosikazu Nakamura and Hiroshi Yanagawa of the Department of Public Health, Jichi Medical School, Tochigi, Japan. (Prof. Yanagawa et al. had organized a nationwide investigation group for KD at the end of 1960, and started the large-scale epidemiological investigation of KD in Japan). The group reported the results from the nationwide survey of KD in Japan (henceforth called KD-NSR) every 2 years, from 1970 [3]. We calculated the date of onset for each patient and summed up the KD Pt.Nos. for each month of the 12-year span, without description of personal information.

\section{Pollen Data}

Data for Po.Nos. (count $\cdot \mathrm{cm}^{-2}$ ) for each species, which had been surveyed daily at the National Hospital Organization Sagamihara National Hospital (NHOSNH) in Sagamihara City, Kanagawa, Japan, were kindly provided by Dr. Hiroshi Yasueda. The pollen species included those of the Japanese cedar (Cryptomeria japonica), Japanese cypress, Japanese zelkova, ginkgo, saw tooth oak, rice, ragweed, Japanese hop, and other identified and unidentified pollens. We summed up the Po.Nos. for all species and for Japanese cedar of each month from 1991 to 2002, as shown in Table 1C.

\section{Statistical Analyses of the Correlation of Po. Released and KD Pt. Development}

The relation between monthly sums of Po.Nos. surveyed at NHOSNH and monthly sums of KD Pt.Nos. from all parts of Kanagawa was investigated. Patients were from the farthest end of Kanagawa, spanning an area $51 \mathrm{~km}$ southwest of NHOSNH to $29 \mathrm{~km}$ east of NHOSNH during 12 years, from 1991 to 2002 (Supportive Material). We made comparative graphs between the monthly Po.Nos. and the monthly KD
Pt.Nos. for 144 months, which indicated seasonal variation patterns of both pollen exposure and $\mathrm{KD}$ development (shown in Fig. 1). Correlation coefficients (c.c.) of the relation between the 2 phenomena were analyzed. Using the Excel function, we performed regression analyses and multiple regression analyses of the association between Po.Nos. in certain months or 3 consecutive months (October, November, and December), and KD Pt.Nos. in the subsequent 1012 months individually and each month in the subsequent 4 years.

\section{Design for Statistical Analyses}

We examined the correlation between the 2 phenomena from several angles by (1) investigating the broad overview of seasonal variation pattern; (2) generating a c.c. matrix between all species of Po.Nos. or Japanese cedar Po.Nos. for individual months, and KD Pt.Nos. for each month; (3) analyzing the correlation between Po.Nos. in March and KD Pt.Nos. summed up for several months; (4) calculating the distribution of all species and Japanese cedar Po.Nos. in each month, and comparing cedar pollen\% in February, March, and April; (5) analyzing the effect of Japanese cedar Po.Nos. in March, and also from October to December on KD Pt.Nos., as compared with the effect of Po.Nos. from all species in March; and (6) drawing attention to the cumulative effect of the Po.Nos. of all species in March for 1-5 years, on KD Pt.Nos..

\section{RESULTS}

A graph comparing the monthly Po.Nos. to the monthly KD Pt.Nos. during the 144 months spanning 1991 to 2002, is shown in Fig. (1(A)), and a scale-up graph of this comparison during 1997-2002 is shown in Fig. (1(B)). The graph in Fig. (1(B)) shows a typical pattern of waves for the occurrence of KD and its correlation with monthly movements of pollen release over several years. The percent Po.Nos. of all species, the percent Po.Nos. of Japanese cedar, and the percent KD Pt.Nos. for each month is shown in Table $\mathbf{1 A}$. About $80 \%$ of the annual pollen from all species is released in March and April. In March, the pollen is mainly contributed by Japanese cedar (Cryptomeria japonica), while in April, the pollen is derived from several species including the Japanese cedar, Japanese cypress, Japanese zelkova, ginkgo, and sawtooth oak. In September, some pollen release from rice, ragweed, and Japanese hop is observed, and it is greatest $(3.79 \%)$ during the months June-January. It is notable that $76.12 \%$ of the annual cedar Po.Nos. is released in March.

\section{Correlation of Pollen-Release Patterns and Monthly Changes in the Development of KD from 1991 to 2002}

After a peak of extensive seasonal pollen release, gentle high plateaus of KD Pt.Nos. (2 or 3 waves) appeared from March or April, extended to August, and decreased in September. After a nadir in September or October, sharp peaks extending from November to February drastically entered a decreasing phase during February and March. Both peaks seemed to belatedly coincide with the Po.Nos. peaks of March and April. Time lags of peaks were recognized to be present between Po.Nos. and KD Pt.Nos. Total patient numbers during March to August (52.04\% in Table 1A) in gentle 


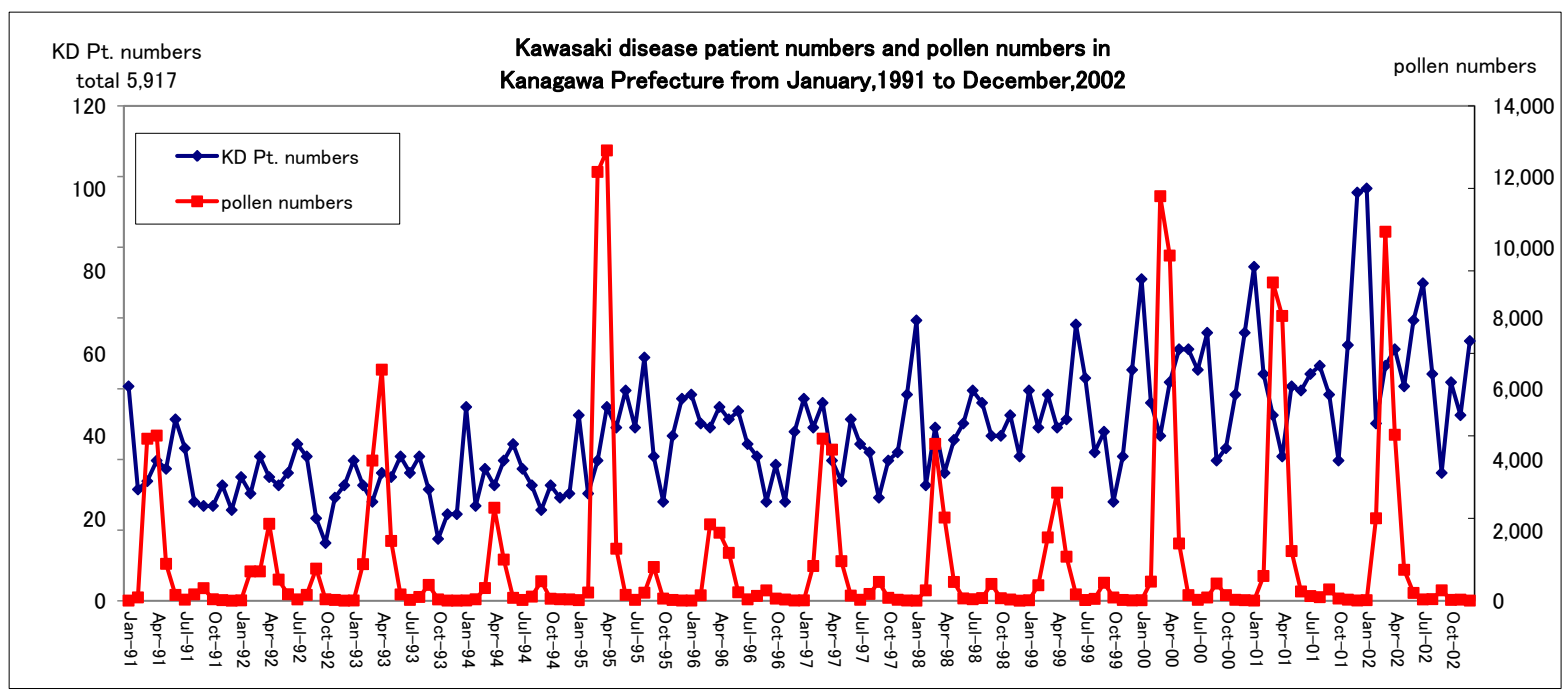

(A)

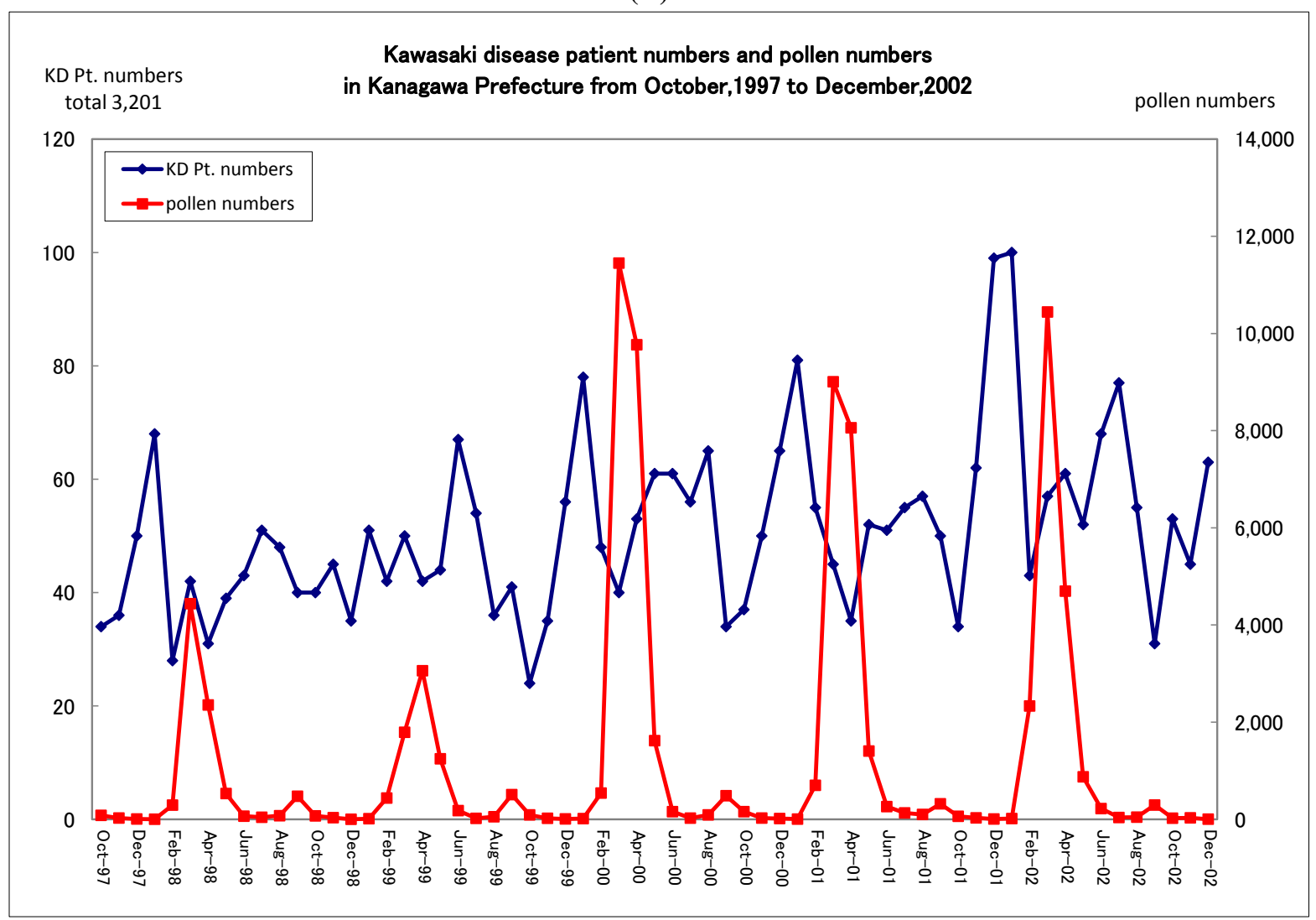

(B)

Fig. (1). Kawasaki disease patient numbers, and pollen numbers in Kanagawa Prefecture from January,1991 to December, 2002 (A), and from October,1997 to December, 2002 (B).

Table 1A. Percent of Pollen Numbers(Po.Nos.) and Number of KD Patient(KD Pt.Nos.) for Each Month from 1991 to 2002

\begin{tabular}{|c|c|c|c|c|c|c|c|c|c|c|c|c|c|}
\hline & January & February & March & April & May & June & July & August & September & October & November & December & Total \\
\hline $\begin{array}{l}\text { Po. Nos. of all } \\
\text { species }\end{array}$ & 0.08 & 4.74 & 40.58 & 38.83 & 8.72 & 1.27 & 0.29 & 0.93 & 3.79 & 0.49 & 0.20 & 0.07 & $100.00 \%$ \\
\hline Cedar Po. Nos. & 0.06 & 10.17 & 76.12 & 13.32 & 0.08 & 0.01 & 0.00 & 0.01 & 0.01 & 0.03 & 0.10 & 0.10 & $100.00 \%$ \\
\hline KD Pt. Nos. & 11.58 & 7.28 & 8.08 & 7.99 & 8.23 & 9.79 & 9.28 & 8.67 & 6.29 & 6.07 & 7.37 & 9.38 & $100.00 \%$ \\
\hline
\end{tabular}


Table 1B. All Species of Pollen and Cedar Pollen Numbers, and Cedar Pollen\% in February, March, and April from 1991 to 2002

\begin{tabular}{|c|c|c|c|c|c|c|c|c|c|}
\hline Year & \multicolumn{3}{|c|}{ February } & \multicolumn{3}{|c|}{ March } & \multicolumn{3}{|c|}{ April } \\
\hline 1991 & 94.44 & 79.94 & 84.6 & 4584.88 & 4422.22 & 96.5 & 4674.21 & 484.57 & 10.4 \\
\hline 1992 & 831.48 & 784.26 & 94.3 & 831.17 & 629.63 & 75.8 & 2177.69 & 28.70 & 1.3 \\
\hline 1993 & 1035.80 & 1021.91 & 98.7 & 3966.67 & 3175.31 & 80.0 & 6539.20 & 549.38 & 8.4 \\
\hline 1994 & 41.67 & 31.17 & 74.8 & 359.88 & 303.40 & 84.3 & 2632.25 & 104.63 & 4.0 \\
\hline 1996 & 154.32 & 148.46 & 96.2 & 2161.73 & 2062.35 & 95.4 & 1925.31 & 155.56 & 8.1 \\
\hline 1997 & 983.64 & 950.00 & 96.6 & 4587.21 & 3955.56 & 86.2 & 4276.54 & 863.89 & 20.2 \\
\hline 1998 & 293.83 & 284.26 & 96.7 & 4439.24 & 3397.22 & 76.5 & 2354.63 & 75.62 & 3.2 \\
\hline 1999 & 439.51 & 427.47 & 97.3 & 1792.59 & 1386.42 & 77.3 & 3058.95 & 134.88 & 4.4 \\
\hline Total count $/ \mathrm{cm}^{2}$ & 7684.56 & 7470.68 & & 65753.09 & 55914.41 & & 62904.59 & 9787.79 & \\
\hline mean \pm S.D. count $/ \mathrm{cm}^{2}$ & $\begin{array}{c}640.38 \pm \\
606.26\end{array}$ & $\begin{array}{c}622.56 \pm \\
604.01\end{array}$ & & $\begin{array}{c}5479.42 \pm \\
4024.42\end{array}$ & $\begin{array}{c}4659.53 \pm \\
3559.00\end{array}$ & & $\begin{array}{c}5242.05 \pm \\
3268.66\end{array}$ & $\begin{array}{c}815.65 \pm \\
1090.77\end{array}$ & \\
\hline \multicolumn{3}{|c|}{ Cedar $\%$ mean \pm S.D. } & $93.8 \pm 6.8$ & & & $84.3 \pm 9.9$ & & & $10.9 \pm 8.8$ \\
\hline
\end{tabular}

Table 1C. All Species of Pollen and Cedar Pollen Numbers in Each Month from 1991 to 2002

\begin{tabular}{|c|c|c|c|c|c|c|c|c|c|c|c|c|c|}
\hline \multirow{2}{*}{ Year } & \multirow{2}{*}{$\begin{array}{c}\begin{array}{c}\text { All } \\
\text { Species }\end{array} \\
\text { Cedar }\end{array}$} & \multicolumn{12}{|c|}{ Po. Release Months } \\
\hline & & January & February & March & April & May & June & July & August & September & October & November & December \\
\hline \multirow{2}{*}{1991} & $\begin{array}{c}\text { all } \\
\text { species }\end{array}$ & 4.89 & 94.44 & 4584.88 & 4674.21 & 1044.62 & 166 & 32 & 180.56 & 356.79 & 42.59 & 17.9 & 2.78 \\
\hline & cedar & 3.09 & 79.94 & 4422.22 & 484.57 & 7.94 & 0 & 0 & 0.31 & 0.93 & 1.85 & 2.16 & 0.62 \\
\hline \multirow{2}{*}{1992} & $\begin{array}{c}\text { all } \\
\text { species }\end{array}$ & 11.42 & 831.48 & 831.17 & 2177.69 & 598.77 & 184.26 & 39.2 & 167.28 & 909.26 & 42.2 & 23.77 & 4.01 \\
\hline & cedar & 0.93 & 784.26 & 629.63 & 28.7 & 1.23 & 0 & 0 & 0.31 & 0 & 0 & 1.23 & 0.93 \\
\hline \multirow{2}{*}{1993} & $\begin{array}{c}\text { all } \\
\text { species }\end{array}$ & 8.95 & 1035.8 & 3966.67 & 6539.2 & 1692.9 & 178.7 & 24.69 & 107.72 & 448.88 & 38.27 & 5.86 & 4.32 \\
\hline & cedar & 1.23 & 1021.91 & 3175.31 & 549.38 & 5.56 & 0.62 & 1.23 & 0.31 & 0.62 & 1.54 & 0.62 & 0.31 \\
\hline \multirow{2}{*}{1994} & $\begin{array}{c}\text { all } \\
\text { species }\end{array}$ & 8.95 & 41.67 & 359.88 & 2632.25 & 1165.28 & 82.98 & 23.15 & 117.59 & 552.47 & 57.72 & 43.52 & 38.55 \\
\hline & cedar & 0.31 & 31.17 & 303.4 & 104.63 & 0.62 & 0.31 & 0 & 0.31 & 0 & 3.09 & 30.56 & 27.44 \\
\hline \multirow[t]{2}{*}{1995} & $\begin{array}{c}\text { all } \\
\text { species }\end{array}$ & 18.24 & 232.72 & 12134.04 & 12742.35 & 1472.53 & 166.98 & 25.62 & 228.4 & 955.31 & 61.3 & 23.15 & 6.79 \\
\hline & cedar & 12.07 & 218.21 & 11415.03 & 3721.42 & 11.42 & 0.93 & 0 & 0.93 & 1.54 & 1.54 & 1.23 & 2.47 \\
\hline \multirow[t]{2}{*}{1996} & $\begin{array}{c}\text { all } \\
\text { species }\end{array}$ & 6.48 & 154.32 & 2161.73 & 1925.31 & 1355.56 & 239.81 & 40.41 & 138.27 & 293.52 & 61.73 & 35.49 & 8.02 \\
\hline & cedar & 1.54 & 148.46 & 2062.35 & 155.56 & 1.85 & 0.93 & 0 & 0 & 0 & 0.62 & 9.88 & 4.94 \\
\hline \multirow{2}{*}{1997} & $\begin{array}{c}\text { all } \\
\text { species }\end{array}$ & 11.73 & 983.64 & 4587.21 & 4276.54 & 1120.71 & 145.99 & 27.46 & 192.59 & 533.64 & 83.33 & 28.09 & 8.33 \\
\hline & cedar & 4.63 & 950 & 3955.56 & 863.89 & 5.25 & 0.93 & 0 & 0 & 0.93 & 1.85 & 3.7 & 6.17 \\
\hline
\end{tabular}


Table 1C. contd...

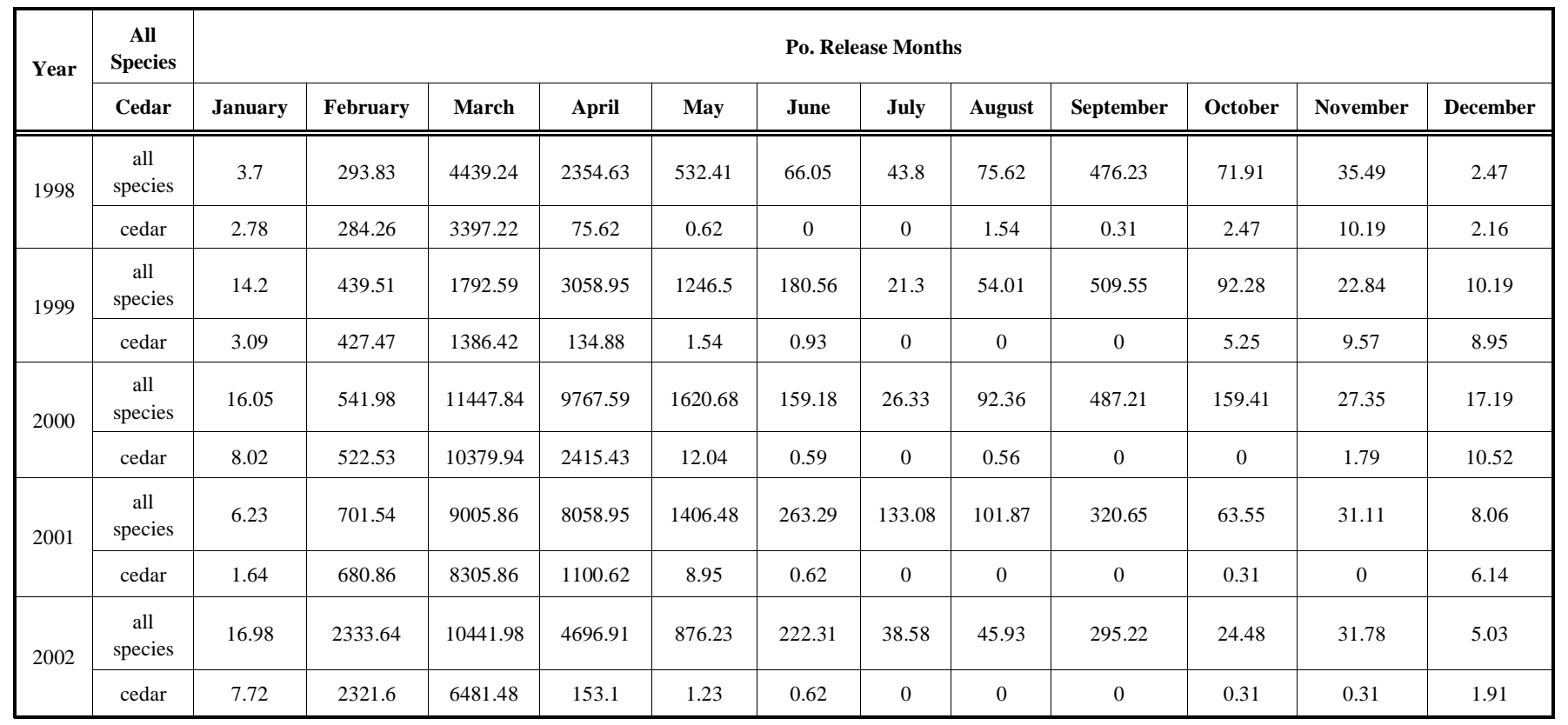

Table 2. Correlation Coefficient Matrix Between the Number of Pollen Released from All Species and Number of KD Patients

\begin{tabular}{|c|c|c|c|c|c|c|c|c|c|c|c|c|c|}
\hline \multirow{2}{*}{$\begin{array}{l}\text { KD } \\
\text { Development } \\
\text { According to } \\
\text { Month }\end{array}$} & \multicolumn{13}{|c|}{ All Species of Po. Release Month } \\
\hline & January & February & March & April & May & June & July & August & September & October & November & December & $\begin{array}{c}\text { Mean } \pm \\
\text { S.D. }\end{array}$ \\
\hline January & 0.16 & 0.20 & 0.46 & 0.35 & 0.41 & 0.37 & 0.55 & 0.46 & 0.32 & $0.61^{*}$ & 0.16 & 0.09 & $0.35 \pm 0.14$ \\
\hline February & 0.14 & 0.32 & 0.55 & 0.37 & 0.24 & 0.20 & 0.19 & 0.40 & 0.08 & $0.75^{*}$ & 0.26 & 0.03 & $0.29 \pm 0.14$ \\
\hline March & 0.32 & 0.33 & 0.50 & 0.26 & 0.21 & 0.24 & $0.60 *$ & 0.29 & 0.52 & 0.38 & 0.42 & 0.10 & $0.35 \pm 0.14$ \\
\hline April & $0.66^{*}$ & 0.46 & $0.66^{*}$ & 0.36 & 0.10 & 0.15 & 0.56 & 0.36 & 0.03 & 0.11 & 0.41 & 0.28 & $0.35 \pm 0.21$ \\
\hline May & 0.36 & 0.19 & $0.68 *$ & 0.44 & 0.33 & 0.04 & 0.20 & 0.37 & 0.02 & $0.63^{*}$ & 0.18 & 0.26 & $0.31 \pm 0.20$ \\
\hline June & 0.56 & 0.35 & 0.55 & 0.28 & 0.20 & 0.32 & 0.50 & $0.66^{*}$ & 0.25 & 0.38 & 0.49 & 0.16 & $0.39 \pm 0.15$ \\
\hline July & 0.41 & $0.62 *$ & $0.58^{*}$ & 0.15 & 0.17 & 0.31 & 0.28 & 0.48 & 0.42 & 0.47 & 0.35 & 0.07 & $0.36 \pm 0.16$ \\
\hline August & 0.50 & 0.30 & $0.88^{*}$ & $0.70^{*}$ & 0.23 & 0.22 & 0.34 & 0.21 & 0.18 & $0.60^{*}$ & 0.44 & $0.62 *$ & $0.44 \pm 0.22$ \\
\hline September & 0.03 & 0.02 & 0.48 & 0.39 & 0.17 & 0.20 & $0.61 *$ & 0.44 & 0.20 & $0.84 *$ & 0.47 & 0.36 & $0.35 \pm 0.23$ \\
\hline October & 0.13 & 0.45 & 0.48 & 0.01 & 0.20 & 0.05 & 0.21 & 0.48 & 0.53 & 0.15 & 0.15 & 0.04 & $0.24 \pm 0.18$ \\
\hline November & 0.17 & 0.23 & $0.72 *$ & 0.49 & 0.05 & 0.21 & $0.64 *$ & 0.31 & 0.19 & 0.39 & 0.27 & 0.41 & $0.34 \pm 0.19$ \\
\hline December & 0.27 & 0.29 & $0.61^{*}$ & 0.12 & 0.26 & 0.55 & $0.69^{*}$ & 0.31 & 0.26 & 0.35 & 0.25 & 0.05 & $0.36 \pm 0.17$ \\
\hline Mean \pm S.D. & $\begin{array}{c}0.31 \pm \\
0.19\end{array}$ & $\begin{array}{c}0.31 \pm \\
0.15\end{array}$ & $\begin{array}{c}0.60 \pm \\
0.12\end{array}$ & $\begin{array}{c}0.35 \\
\pm \\
0.16\end{array}$ & $\begin{array}{c}0.21 \\
\pm \\
0.09\end{array}$ & $\begin{array}{c}0.24 \\
\pm \\
0.13\end{array}$ & $\begin{array}{c}0.45 \\
\pm \\
0.18\end{array}$ & $\begin{array}{c}0.40 \pm \\
0.11\end{array}$ & $0.25 \pm 0.16$ & $\begin{array}{c}0.47 \pm \\
0.21\end{array}$ & $0.32 \pm 0.12$ & $\begin{array}{c}0.21 \pm \\
0.18\end{array}$ & \\
\hline
\end{tabular}

*statistically significant at $\mathrm{p}<0.05$.

high plateaus were larger than those during October to January $(34.4 \%)$ in sharp peaks in Fig. (1).

\section{C.c. Matrix Between Number of Pollen Released and Number of KD Patients}

Correlation was examined between Po.Nos. and KD Pt.Nos. in each month, by generating a c.c. matrix. As shown in Table 2, there were 6 months in which c.c. associations between Po.Nos. of all species in March and KD Pt.Nos. were significant $(\mathrm{p}<0.05)$. The c.c. values in descending order were 0.88 in August, 0.72 in November, 0.68 in May,
0.66 in April, 0.61 in December, and 0.58 in July. The number of significant c.c. associations between Po.Nos. and KD Pt.Nos. and mean c.c. values were found to be at a maximum in March (0.60). The c.c. value of 0.50 between Po.Nos. in March and KD Pt.Nos. in the same month was comparatively smaller. The c.c. value of 0.70 between Po.Nos. in April and KD Pt.Nos. in August was significant. The c.c. value of 0.62 between Po.Nos. in February and KD Pt.Nos. in July was significant. Although the Po.Nos. in October and July were small $(0.49 \%$ and $0.29 \%$, respectively), of the 12 months (Table 1A), the mean c.c. in October (0.47) was 
Table 3. Correlation Coefficient Between the Number of all Species and Cedar Pollen Release in March, and Number of KD patients

Pollen Release by All Species

\begin{tabular}{|c|c|c|c|}
\hline KD Development According to Month & c.c. & KD Development According to Month & c.c. \\
\hline \hline March-May & $0.63^{*}$ & August-October & $0.77^{*}$ \\
\hline April-June & $0.68^{*}$ & September-November & $0.66^{*}$ \\
\hline May-July & $0.65^{*}$ & October-December & $0.68^{*}$ \\
\hline June-August & $0.76^{*}$ & March-December & $0.73^{*}$ \\
\hline July-September & $0.76^{*}$ & April-December & $0.75^{*}$ \\
\hline
\end{tabular}

*statistically significant at $\mathrm{p}<0.05$.

Cedar Pollen Release

\begin{tabular}{|c|c|c|c|}
\hline KD Development According to Month & c.c. & KD Development According to Month & c.c. \\
\hline \hline March-May & 0.52 & August-October & $0.70^{*}$ \\
\hline April-June & $0.59^{*}$ & September-November & $0.60^{*}$ \\
\hline May-July & 0.54 & October-December & $0.62^{*}$ \\
\hline June-August & $0.66^{*}$ & March-December & $0.64^{*}$ \\
\hline July-September & $0.69^{*}$ & April-December & $0.68^{*}$ \\
\hline
\end{tabular}

*statistically significant at $\mathrm{p}<0.05$.

comparatively large, and it was the second highest after March. The mean c.c. in July (0.45) was the third largest, while that in April (0.35) and February (0.31) were ranked fifth and seventh, respectively. On observing the c.c. values of the pollen-release months of March, April, February, October, and July, we noticed that the principal lags between pollen-release months and months of KD development were mainly 1-2 months, 4-5 months, and 8-9 months. Similar results were observed in the analyses of the c.c. matrix between cedar Po.Nos. and KD Pt.Nos. As partly shown in Table 4, the c.c. values were 0.84 in August, 0.70 in November, 0.64 in May, 0.59 in December, 0.56 in April, and 0.54 in February, although the numeric values were slightly lower than those in the analyses of all species for Po.Nos..

\section{Correlation Between Po.Nos. in March and KD Pt.Nos.} for Several Months

Next, the c.c. associations were examined between Po.Nos. in March and KD Pt.Nos. combined from 3 neighboring months, from March to December, and from April to December, in the same year. As shown in Table 3, all the c.c. values were significant $(\mathrm{p}<0.05)$ with respect to the Po.Nos. from all species. The c.c. values of $0.76,0.76$, and 0.77 of the combined months including August, and the c.c. value of 0.75 from April to December were rather large, compared to all the c.c. values. Regarding cedar Po.Nos., almost all c.c. values were significant $(p<0.05)$ except for those of March-May and May-July, although the numeric values were also lesser than those in the analyses of Po.Nos. from all species.

Actual Surveyed Numbers of All Species of Pollen and Japanese Cedar Pollen, and Percent Cedar Pollen from 1991 to 2002

All species of pollen and Japanese cedar Po.Nos. alone in each month from 1991 to 2002 are shown in Table 1C; these were summed up month-by-month by using the NHOSNH daily data. Table 1B shows the percentages of cedar Po.Nos. in the Po.Nos. of all species were generally large, with a mean of $93.8 \%$ in February and $84.3 \%$ in March, and the mean of $10.9 \%$ in April was comparatively lower. A comparatively smaller mean c.c. of 0.35 was consequently found in April (Table 2), although the Po.Nos. of all species in April was similar (38.83\%) to that in March (40.58\%) (Table 1A). Similarly, the percentage of the annual cedar Po.Nos. in May was only $0.08 \%$ (Table $\mathbf{1 A}$ ), thus a smallest mean c.c. of 0.21 was also found. The NHOSNH survey revealed that Japanese cedar pollen began to be released in October, and a small amount of the initial release continued from late autumn through late winter before the extensive seasonal pollen release (Table $\mathbf{1 C}$ ). This phenomenon was more distinct in the autumn of 1994 when the temperatures in summer were extremely high.

Effect of Japanese Cedar Po.Nos. in March and That from October to December on KD Pt.Nos. as Compared with the Po.Nos. of All Species in March

As the percentages of KD Pt.Nos. in December and January were somewhat higher (Table 1A) and the mean c.c. of October (0.47) was the second largest (Table 2), we queried whether the effects of the additional Po.Nos. from the forerunning cedar pollen in October, or the net sum of cedar Po.Nos. totaled from October, November, and December, were associated with this greater KD Pt.Nos. To this end, we examined a possible association by using multiple linear regression analysis for each month or each set of months (Table 4). The c.c. values between merged Po.Nos. and KD Pt. Nos. in November (0.73) and December (0.65) were found to show a trend of association $(\mathrm{p}<0.1)$. Because the percentages of cedar Po.Nos. in March, October, November, and December were $76.12,0.03,0.10$, and 0.10 , respectively (Table 1A), the c.c. value between Po.Nos. of cedar in October and also the c.c. between the sum of cedar Po.Nos. totaled from October to December, and the KD Pt. Nos. of each month were, as a whole, lower than the c.c. between 
Table 4. Effect of Cedar Po. No. in March, and October on KD Pt. Nos. as Compared with Po. Nos. of All Species in March

\begin{tabular}{|c|c|c|c|c|c|c|}
\hline $\begin{array}{c}\text { KD Development } \\
\text { According to } \\
\text { Month }\end{array}$ & $\begin{array}{c}\text { All Species in } \\
\text { March }\end{array}$ & Cedar in March & Cedar in October & $\begin{array}{c}\text { All Species in } \\
\text { March + Cedar in } \\
\text { October }\end{array}$ & $\begin{array}{c}\text { Cedar from } \\
\text { October to } \\
\text { December }\end{array}$ & $\begin{array}{c}\text { All species in March } \\
+ \text { Cedar from } \\
\text { October to December }\end{array}$ \\
\hline \hline January & 0.46 & 0.44 & 0.00 & 0.50 & 0.04 & 0.09 \\
\hline February & $0.55^{*}$ & $0.54^{*}$ & 0.02 & 0.59 & 0.49 \\
\hline March & $0.50^{*}$ & 0.49 & 0.09 & 0.51 & 0.07 & 0.57 \\
\hline April & $0.66^{* *}$ & $0.56^{*}$ & 0.33 & 0.52 & 0.32 & 0.53 \\
\hline May & $0.68^{* *}$ & $0.64^{* *}$ & 0.43 & 0.72 & 0.23 & 0.26 \\
\hline June & $0.55^{*}$ & 0.46 & 0.30 & 0.46 & 0.51 \\
\hline July & $0.58^{* *}$ & 0.43 & 0.07 & 0.44 & 0.06 & 0.43 \\
\hline August & $0.58^{* *}$ & $0.84^{* *}$ & 0.40 & 0.45 & $0.57^{* *}$ & 0.44 \\
\hline September & 0.48 & 0.49 & 0.05 & 0.26 & 0.29 & $0.65^{*}$ \\
\hline October & 0.48 & 0.33 & 0.21 & 0.48 & 0.09 & 0.48 \\
\hline November & $0.72^{* *}$ & $0.70^{* *}$ & 0.24 & 0.73 & 0.31 & 0.46 \\
\hline December & $0.61^{* *}$ & $0.59^{* *}$ & 0.25 & 0.61 & 0.22 & 0.53 \\
\hline
\end{tabular}

**statistically significant at $\mathrm{p}<0.05$. (*at $\mathrm{p}<0.1)$

Table 5. Correlation Coefficient Between Pollen Release by All Species in March 1-5 years, with the Number of KD Patients

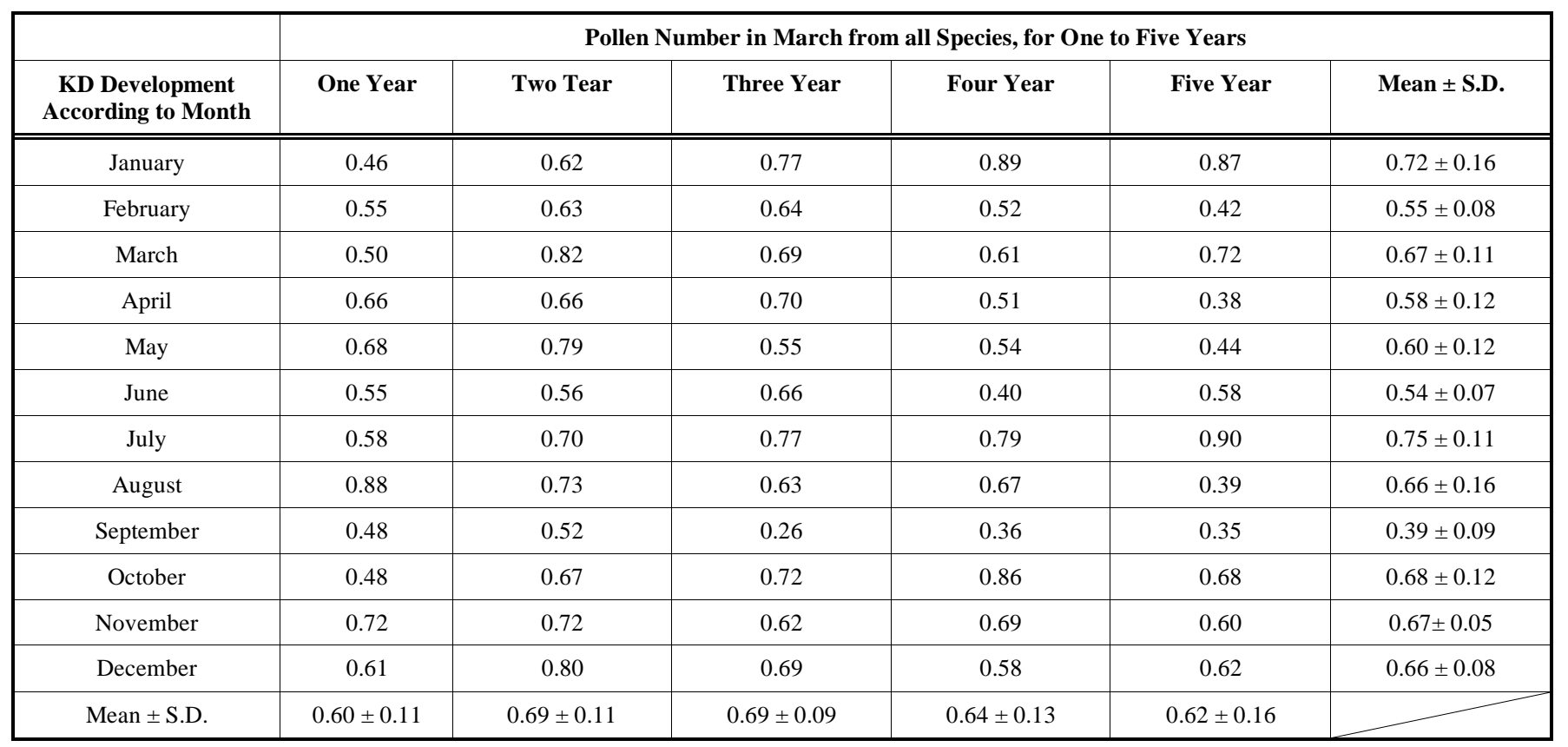

cedar Po.Nos. in March and KD Pt. Nos. of each month. A significant c.c. value of $0.57(p<0.05)$ was found between the KD Pt.Nos. in August and the cedar Po.Nos. totaled from October to December. In terms of c.c. association, the effect of additional cedar Po.Nos. in October, or from the 3 months totaled from October to December, was not clear.

\section{C.c. Between Po.Nos. of All Species in March for 1-5 years and KD Pt.Nos.}

In the time periods following the years in which large quantities of pollen was released was observed (such as in 1995), the KD Pt.Nos. remained somewhat high, even if the Po.Nos. in the subsequent years were less. To examine a possible carry-over effect, the cumulative effect of year-by-year Po.Nos. from all species in March on KD Pt.Nos. was further studied (Table 5). The mean c.c. values between the total Po.Nos. in March and KD Pt.Nos. of each month in 2 years tended to be greater $(0.69 \pm 0.09)$ than that of 1 year $(0.60 \pm$ $0.11)$; however, the difference was not statistically significant. The mean c.c. of the Po.Nos. from 3 and 4 years in March also showed a slightly increased trend compared with that for 1 year. Similarly, the accumulative effects of the Po.Nos. over 1-5 years from all species in March seemed to correlate with the KD Pt.Nos. in January and July (means, 0.72 and 0.75 , respectively). 
To summarize, since the Po.Nos. from all species in February, March, and April were 4.7\%, 40.6\%, and 38.8\%, respectively, and the cedar Po.Nos. in these months were $93.8 \%, 84.3 \%$, and $10.9 \%$, respectively, the significant correlation between Po.Nos. and KD Pt.Nos. in March may be mainly attributable to the release of cedar pollen, although pollen from other sources are also partly contributory.

\section{DISCUSSION}

From this study on seasonal variation patterns of KD onset and pollen release in Kanagawa during the period from 1991 to 2002, it was elucidated that KD Pt.Nos. strongly correlated with the Po.Nos. of all species, especially that of Japanese cedar, released mainly in March, and partly in February and April. In our previous 2 papers, we proposed that the causative substances involved in and responsible for the occurrence of KD may be pollens [7, 9], and that one suppressive factor in this association may be Infl epidemics, as $\mathrm{KD}$ occurrence decreased in the peak months of Infl epidemic [9]. Since the c.c. values obtained in association studies using Po.Nos. from all species were generally larger than the c.c. values found in the comparisons of Po.Nos. from cedar in March, the contribution of pollen other than cedar pollen to KD development was hypothesized.

Distinct lag times are evident between pollen exposure and KD development in the monthly dynamics of the 2 phenomena. Belated KD outbreaks, such as the peaks from April to August, and peaks from November to January are preceded by peaks of pollen release in every year, as shown in Fig. (1) and Table 2. This association pattern differs from the case of Japanese cedar pollinosis, whose occurrence is temporally matched with pollen release, which is a type I (or immediate) hypersensitivity reaction [10]. KD may be some kind of sub-acutely or chronically developed "delayed-type hypersensitivity" PID, since the association between Po.Nos. in March and the KD Pt.Nos. in March was rather small, with a c.c. value of 0.50 (Table 2). However, it is possible that a delayed-type hypersensitive response was masked by the addition of a persistent suppressive effect on KD outbreaks caused by Infl epidemics around February [9].

These findings suggest that the onset of KD may be " delayed-type hypersensitively", but slowly progressed in infants resensitized with pollen exposure following the first sensitization mainly via respiratory tract, different from a few days of tuberculin reaction in the skin test after BCG vaccination (5). It has been known that at the same time of KD development, BCG inoculation site inflammation, ie, BCG reactivation such as skin redness and swelling like tuberculin reaction, and ulceration and lesion happen in patients $[3,5]$. These phenomena remind us increased systemic hyperimmune responses of "delayed-type hypersensitivity" triggered originally by pollen exposure and parallellypropagated throughout the body. To determine the mechanism of KD, it will be necessary to study and demonstrate blastoid transformation of lymphocytes sensitized with specific antigenic constituents of pollens such as Cry j1 and Cry $\mathrm{j} 2$ in $\mathrm{KD}$ patients $[11,12]$.

Awaya et al. reported in 2002 that individuals exhibiting conspicuous nevi are resistant to pollinosis, but those who do not show increased susceptibility to pollinosis [13]. Synner- stad et al. reported that fewer melanocytic nevi were found in children with active atopic dermatitis than in children without dermatitis [14]. Referring to these two papers, Awaya pointed out that individuals who have suffered from KD during their childhood, exhibit soft skin conditions in head and neck and don't show conspicuous nevi on the head and neck, and are almost all already suffering from pollinosis or other allergic diseases before becoming adults [15]. Further studies are needed in order to clarify the process of the immune response in infants suffering from KD. For example, it is not known if $\mathrm{KD}$ onset is preceded by a type I allergic disease such as a food allergy, bronchial asthma, atopic dermatitis, or allergic rhinitis. More epidemiological studies are also essential for examining the association of KD and the onset of future pollinosis or other allergic diseases.

Many patients in Japan are also affected by immediate type I hypersensitivity of pollinosis when exposed to even small quantities of Japanese cedar pollen released during October-January preceding the months of February-April. Meanwhile, most patients are affected by a delayed-type hypersensitivity of KD in December and January (Table 1 and Fig. 1). Thus, some additional effects of forerunning cedar pollen during October-January to pollens from all species in March on KD development were examined by multiple linear regression analysis. The results did not show a clear association (Table 4), probably because of the brevity of the surveillance period. Alternatively, it is possible that the start of Infl epidemics in December and January reduced the c.c. values, as a sharp transient valley of KD Pt.Nos. was successively observed in February during Infl epidemics [9].

Thus, a series of peaks of KD onset extending from April to August after or during a massive seasonal pollen release, with a low in September and October, and peaks from November to January after or during autumn pollen release, had a characteristic valley around February, when peaks of Infl epidemics occurred each year [9]. A trilateral correlation analysis of KD Pt.Nos., Infl Pt.Nos., and Po.Nos. may be therefore, needed for a more accurate understanding of the transition of KD development in each year. Cross-correlation analyses between KD Pt.Nos. and Po.Nos. have been separately done using software Matlab. Similar results have been obtained and will be reported elsewhere [unpublished data].

From the monthly and annual patterns of KD onset and c.c. matrix (Fig. 1, Table 2, and Table 3), it may be possible to understand how newborns and young children might develop $\mathrm{KD}$. Based on the pollen and $\mathrm{KD}$ onset distributions patterns, babies with a family history of allergies, born in January or February, mere for example, may develop KD if the infants were sensitized with the first pollen exposure during the high amount of pollen release in February, March, and April. These children may be resensitized with pollen exposure in April and May, or in the months of June, July, or August, resulting in the development of KD. Children who did not develop KD during these periods were resensitized with pollen exposure by the forerunning pollen release from October to January, with the result that they developed KD in November-January. Children who did not develop KD in the first year may be resensitized with pollen exposure after a "carry-over period" in early spring, resulting in their developing KD in March, April, or May in the next year. 
Clearly, it is critically important to protect babies and young children having allergic tendencies from pollen exposure-induced KD. The data presented here provide a framework for making an informed prediction of the months in which sensitization would most likely occur, and when the development of KD symptoms should be closely monitored.

According to KD-NSR, about $80 \%$ of patients who developed KD were under 3 years of age [9]. Specifically, $25 \%$ of patients were less than a year old, $25 \%$ were 12 to 23 months of age, $18 \%$ were 2 -year-olds, and $12 \%$ were 3 -yearolds. In the study of KD, only a short period of time (3 or 4 years) of observation and surveillance range is required to examine the environmental causes and effects, different from other illnesses of uncertain etiology in the fact that it may occur in an elderly and much wider age range of people. Using the methodology described in this study, other candidate PID showing delayed-type hypersensitivity reactions may be elucidated.

The findings of these studies require further investigations about the mechanisms of KD induction due to exposure to Japanese cedar pollens. In addition to gaining an understanding of the allergic nature of $\mathrm{KD}$, it is also important to clarify cardiovascularly the pathology of systemic vasculitis of KD. For this purpose, generating a KD animal model that incorporates our present observation and genetic background information [16, 17] will be essential. Our epidemiological results will be able to be substantiated only by means of succeeding in making animal models of KD by immunizing animals with pollens, and only through diagnosing by stimulation test of lymphocytes of KD patients with pollen substances during the acute illness.

\section{CONCLUSIONS}

A positive association was demonstrated between the Po.No. from all species, particularly cedar Po.Nos. in March, and the KD Pt.Nos. in the following several months in the spring to summer, and in the late autumn to winter.

\section{DISCLOSURE}

Statement of Conflict of interest: The authors, Awaya and Murayama have declared no competing interests.

\section{FUNDING}

This research received no specific grant from any funding agency in the public, commercial or not-for-profit sectors.

\section{AUTHORS' CONTRIBUTIONS}

Akira Awaya designed all of this work, performed and wrote this manuscript.

The contribution of the coauthor (Koji Murayama) is shared with the first author since he performed statistical analyses.

\section{ACKNOWLEDGEMENTS}

Awaya highly appreciates Professors Yosikazu Nakamura and Hiroshi Yanagawa of Department of Public Health, Jichi Medical School, Tochigi, Japan for providing us with individual data of KD patients. He also greatly ap- preciates Dr. Hiroshi Yasueda, National Hospital Organization Sagamihara National Hospital for suppling us with daily surveyed data of numbers of pollen releases. He owed a lot to Mr. Toru Mori during the first stage of making two species of data base and graphing who is a coauthor of his another manuscript which has been submitted before this article, and not published. He also thanks so much, Mr. Taisei Noguchi, Mr. Yasuhiro Oshima, Mr. Naoya Takemoto, Mr. Shinya Yano and Mr. Kenji Kaneko for data processings.

\begin{tabular}{|c|c|c|}
\hline \\
\hline \multicolumn{3}{|c|}{$\begin{array}{l}\text { ABBREVIATIONS } \\
\text { KD }\end{array}$} \\
\hline Pt. & $=$ & Patients \\
\hline KD Pt.Nos. & $=$ & KD patient numbers \\
\hline Po.Nos. & $=$ & Pollen numbers \\
\hline Cedar pollen & $=$ & Japanese cedar pollen \\
\hline Infl & $=$ & Influenza \\
\hline Kanagawa & $=$ & Kanagawa Prefecture \\
\hline Tokyo & $=$ & Tokyo Metropolis \\
\hline KD-NSR & $=$ & $\begin{array}{l}\text { The results from a nationwide } \\
\text { survey by a nationwide investi- } \\
\text { gation group of KD in Japan }\end{array}$ \\
\hline PID & $=$ & Pollen-induced disease(s) \\
\hline NHOSNH & $=$ & $\begin{array}{l}\text { National Hospital Organization } \\
\text { Sagamihara National Hospital } \\
\text { in Sagamihara City in Kana- } \\
\text { gawa Prefecture }\end{array}$ \\
\hline C.c. & $=$ & Correlation coefficient(s) \\
\hline S.D. & $=$ & Standard deviation \\
\hline
\end{tabular}

\section{LEGEND FOR SUPPORTIVE MATERIAL}

The location of Kanagawa Prefecture near Tokyo Metropolis, Ciba Prefecture, Saitama Prefecture, etc. in Japan and the location of National Hospital Organization Sagamihara National Hospital in Kanagawa Prefecture are shown in the figure.

\section{SUPPORTIVE MATERIAL}

Supplementary material is available on the publisher's web site along with the published article.

\section{REFERENCES}

[1] Kawasaki T. Non-scarlet fever desquamative syndrome. Chiba Med J 1962; 38: 279.

[2] Kawasaki T. Acute febrile muco-cutaneous lymph node syndrome in young children with unique digital desquamation. Jpn J Allergol 1967; 16: 178-222.

[3] Yanagawa H, Nakamura Y, Yashiro M, Kawasaki T, Eds. Epidemiology of Kawasaki Disease-A 30-Year Achievement. (book).Tokyo: Shindan-to-Chiryosha Co. Ltd. 2002.

[4] Horiguchi S, Saito Y. The findings of Japanese cedar pollinosis in Nikko district of Tochigi prefecture. Jpn J Allergol 1964; 13: 16-8.

[5] Nakamura T, Yamamura J, Sato H, Kakinuma H, Takahashi H. Vasculitis induced by immunization with Bacillus Calmette-Guerin followed by atypical mycobacterium antigen: a new mouse model for Kawasaki disease. FEMS Immunol Med Microbiol 2007; 49: 391-7. 
[6] Lee KY, Han JW, Lee JS. Kawasaki disease may be a hyperimmune reaction of genetically susceptible children to variants of normal environmental flora. Med Hypotheses 2007; 69: 642-51.

[7] Awaya A, Sahashi N. The etiology of Kawasaki disease: Does intense release of pollen induce pollinosis in constitutionally allergic adults, while constitutionally allergic infants develop Kawasaki disease? Biomed Pharmacother 2004; 58: 136-40.

[8] Awaya A. The distribution of (immediate and delayed)onset period of Kawasaki disease as one of pollen-induced diseases during 1993-1996. - Epidemiological study of Kawasaki disease No.3-. Proc Jpn Soc Immunol (JSI) 2005; 35: 301.

[9] Awaya A, Mori T. Epidemic of Influenza may suppress development of Kawasaki disease (submitted, 2011).

[10] Okuda M. Epidemiology of Japanese cedar pollinosis throughout Japan. Ann Allergy Asthma Immunol 2003; 91: 288-96.

[11] Kozutsumi D, Tsunematsu M, Yamaji T, Murakami R, Yokoyama M, Kino K. Cry-consensus peptide, a novel peptide for immunotherapy of Japanese cedar pollinosis, induces Th1-predominant response in Cry j 1-sensitized B10.S mice. Biol Pharm Bull 2006; 29 : 2506-9.
[12] Awaya A, Sugane K, Yamauchi J, Kimura M. Stimulation of lymphocytes of patients administered with a trypsin inhibitor, Trasylol(basic pancreatic trypsin inhibitor pharmaceutical), in vitro with BPTI and other several stimulants. Jpn J Exp Med 1975; 45: 541-9.

[13] Awaya A, Watanabe K, Kato S. Individuals exhibiting conspicuous nevi (lentigo simplex) are resistant to allergic rhinitis/conjunctivitis (pollinosis), but those who do not show increased susceptibility to pollinosis. Microbiol Immunol 2003; 47: 101-3.

[14] Synnerstad I, Nilsson L, Fredrikson M, Rosdahl I. Fewer melanocytic nevi found in children with active atopic dermatitis than in children without dermatitis. Arch Dermatol 2004; 140: 1471-5.

[15] Awaya A. On the report from Sweden that fewer melanocytic nevi found in children with active atopic dermatitis. In pursuit of cutting open the paradigm of melanocyte immunology. Allergol Immunol 2005; 12: 1214-7.

[16] Onouchi Y. Identification of susceptibility genes for Kawasaki disease. Nihon Rinsho Meneki Gakkai Kaishi 2010; 33: 73-80.

[17] Onouchi Y. Molecular genetics of Kawasaki disease. Pediatr Res 2009; 65: 46R-54.

(C) Awaya and Murayama; Licensee Bentham Open.

This is an open access article licensed under the terms of the Creative Commons Attribution Non-Commercial License (http://creativecommons.org/licenses/by-nc/3.0/) which permits unrestricted, non-commercial use, distribution and reproduction in any medium, provided the work is properly cited. 